\title{
P-SEPARATION AXIOMS IN SUPRA SOFT TOPOLOGICAL SPACE
}

\author{
Arif Mehmood Khattak', Muhammad Younas², Gulzar Ali Khan ${ }^{2}$, Mujeeb Ur Rehman ${ }^{3}$ Sameena Nadeem $^{3}$ Muhammad Safeer $^{2}$
}

\author{
1 Department of Mathematics and Statistics Riphah International University, Sector I-14 Islamabad, Pakistan \\ ${ }^{2}$ Qurtuba University of Science and Technology Peshawar, Pakistan \\ ${ }^{3}$ Kohat University of Sciences and Technology Department of Mathematics, Pakistan \\ *Corresponding Author Email: mehdaniyal@gmail.com
}

This is an open access article distributed under the Creative Commons Attribution License, which permits unrestricted use, distribution, and reproduction in any medium, provided the original work is properly cited

\section{ARTICLE DETAILS}

\section{Article History:}

Received 12 November 2017 Accepted 12 December 2017 Available online 1 January 2018

\section{ABSTRACT}

The central objective of this article is to introduce soft pre P-separations in soft supra topological spaces. We discuss soft P-separations in soft supra topological spaces with respect to ordinary points and soft points. Further study the hereditary properties at different angles with respect to ordinary points as well as with respect to soft points. Some of their fundamental properties in soft supra topological spaces are also reflected.

\section{KEYWORDS}

soft set, soft point, supra soft topology, soft pre-open set, soft pre-closed set, supra soft separation axioms.

\section{INTRODUCTION}

Many practical problems in economics, engineering, environmental sciences, social sciences, medical sciences etc. cannot be dealt by classical methods because classical methods have inherent difficulties. The reason for these difficulties may be due to the insufficiency of the theories of parameterization tools. Numerous theories exist, for example, fuzzy set theory, intuitionistic fuzzy set theory, rough set theory, i.e., which can be considered as a mathematical tool for dealing with uncertainties. Each of these theories has its inherent difficulties as what were pointed out by Molodtsov in [1-4]. Some researcher originated absolutely a new methodology for modelling uncertainties and applied successfully in directions such as smoothness of functions, game theory, operations research, Riemann-integration, Perron integration, and so on [5]. A group researcher gave the first practical application of soft sets in decision making problems [6]. The algebraic structure of set theories dealing with uncertainty is an important problem. Many researchers have contributed towards the algebraic structure of soft set theory. Some of researchers defined soft groups and deduced their fundamental characterisations [7]. Others group of researchers introduced initial concepts of soft rings [8]. Others group researchers defined soft semi rings and several related notions to establish a connection between soft sets and semi rings [9]. Others group also, defined soft modules and investigated their basic properties [10]. A studied soft ideal over a semi groups which characterized generalized fuzzy ideals and fuzzy ideals with thresholds of a semi groups [11]. There are also some researchers introduced fuzzy soft modules and intuitionistic fuzzy soft modules and investigated some basic properties $[12,13]$

Another group firstly introduced the notion of soft topological space which are defined over an initial universe with a fixed set of parameters and showed that a soft topological space gives a parameterized family of topological spaces [14]. Theoretical studies of soft topological spaces have also been by some authors in [15-18]. In these studies, the concept of soft point is given almost samely. Consequently, some results of classical topology are not valid in soft topological spaces. Another group researchers also introduced the concepts of supra topological spaces, supra closed sets, supra open sets and supra continuous mapping [18] Many results of topological spaces remain valid in supra topological spaces, but some become false.

As a generalized of soft topological spaces, the notion of supra soft topological spaces by dropping only the soft intersection condition [19]. They extend some types of different kinds of subsets of soft topological spaces using the notion of $\gamma$-operation to supra soft topological space and study the decompositions of some forms of supra soft continuity. A researcher also has introduced the notion of soft bi topological space which is defined over an initial universal set $\mathrm{X}$ with fixed set of parameters and studied some types of soft separation axioms [20]. It is clear that a soft bi topological space is a generalization of a soft topological space as every soft bi topological space $\left(X, \eta_{1}, \eta_{2}, E\right)$ if $\eta_{1}=\eta_{2}=\eta$ the notions of soft topological spaces such as open soft sets, closed soft sets, soft interior, and soft closure in a soft bi topological spaces [9]. Thus they introduced the notions of pairwise open (closed) soft sets, pairwise soft interior operator in a soft bi topological space $\left(X, \eta_{1}, \eta_{2}, E\right)$ and showed that the family of all pairwise open soft sets is a supra soft topology which is containing $\eta_{1}, \eta_{2}$ but it is not soft topology [9].

In the present study, we first give some basic ideas about soft sets and the results already studied. In addition to these, we introduce the concept of soft point to the theory of soft set. According to this definition, we investigate some important notions of soft topological spaces. Later we give separability axioms in supra soft topological spaces and study some of their characterizations. The separability axioms are the soft $\mathrm{P}$ separation axioms in supra soft topological spaces with respect to 
ordinary and soft points. We hope that these results will be of greater importance for the forthcoming learning on supra soft topological spaces to accomplish general framework for the practical applications and to solve the most intricate problems containing scruple in economics, engineering, medical, environment and in general mechanic systems of multifarious types.

\section{PRELIMINARIES}

In this section we will introduce necessary definitions and theorems for soft sets. A researcher defined the soft set in the following way [4]. Let X be an initial universe set and $E$ be a set of parameters. Let $P(X)$ denotes the power set of $X$.

Definition 2.1. ([4]) A pair $(F, E)$ is called a soft set over $X$; where $F$ is a mapping given by

$F: E \rightarrow P(X)$.

In other words, the soft set is a parameterized family of subsets of the set $\mathrm{X}$. For $e \in E ; F(e)$ may be considered as the set of $e$-elements of the soft $\operatorname{set}(F ; E)$; or as the set of $e$-approximate elements of the soft set, i.e.

$(F, E)=\{(e, F(e)): e \in E, F: E \rightarrow P(X)\}$.

After this, $S S(X) E_{E}$ denotes the family of all soft sets over $X$ with a fixed set of parameters $E$.

Definition 2.2. ([21]) For two soft sets $(F, E)$ and $(G, E)$ over $X,(F, E)$ is called a soft subset of $(G, E)$ if $\forall e \in E, F(e) \subseteq G(e)$. This relationship is denoted by $(F, E) \widetilde{\widetilde{\subseteq}}(G, E)$.

Similarly, $(F, E)$ is called a soft superset of $(G, E)$ if $(G, E)$ is a soft subset of $(F, E)$. This

Linkage is denoted by $(F, E) \underline{\widetilde{\Xi}}(G, E)$. Two soft sets $(F, E)$ and $(G, E)$ over $X$ are called soft equal if $(F, E)$ is a soft subset of $(G, E)$ and $(G, E)$ is a soft subset of $(F, E)$.

Definition 2.3. ([21]) The intersection of two soft sets $(F, E)$ and $(G, E)$ over $X$ is the soft set

$(H, E)$, where $\forall e \in E, \quad H(e)=F(e) \cap G(e)$. This is denoted $\operatorname{by}(F, E) \widetilde{\widetilde{n}}(G, E)=(H, E)$.

Definition 2.4. ([21]) The union of two soft sets $(F, E)$ and $(G, E)$ over $X$ is the soft set $(H, E)$

Where $\forall e \in E, \quad H(e)=F(e) \cup G(e)$ : This is denoted by $(F, E) \widetilde{\widetilde{U}}(G, E)=(H, E)$.

Definition 2.5. ([13]) A soft set $(F, E)$ over $X$ is said to be a null soft set denoted by $\varphi$ if for alle $\in E, F(e)=\varphi$.

Definition 2.6. ([13]) A soft set $(F, E)$ over $X$ is said to be an absolute soft set denoted by $\tilde{X}$

If for alle $\in E ; F(e)=X$.

Definition 2.7. ([13]) The complement of a soft set $(F, E)$; denoted by $(F, E)^{c}$, is defined as $(F, E)^{c}=\left(F^{c} ; E\right)$; where $F^{c}: E \rightarrow P(X)$ is a mapping given $\operatorname{by} F^{c}(e)=X \backslash F(e) ; \forall e \in E$ and $F^{c}$ is called the soft complement function of $\mathrm{F}$ :

Definition 2.8. ([13]) Let $Y$ be a non-empty subset of $X$, then $\tilde{Y}$ denotes the soft set $(Y, E)$ over $X$ for which $Y(e)=Y$, for all $\in E$.

Definition 2.9. ([13]) Let $(F, E)$ be a soft set over $X$ and $Y$ be a non-empty subset of $X$. Then

The sub soft set of $(F, E)$ over $Y$ denoted by $\left({ }^{Y} F, E\right)$, is defined as follows Y $F(e)=Y \cap F(e)$, for all $\forall e \in E$

In other words $\left({ }^{Y} F, E\right)=\tilde{\tilde{Y}} \cap F(e)$

Definition 2.10. ([13]) Let $\Im$ be the collection of soft sets over X, then $\Im$ is said to be a soft

topology on $X$ if

(1) $\varphi, \tilde{X} \in \mathfrak{J}$

(2) The union of any number of soft sets in $\mathfrak{I}$ belongs to $\mathfrak{I}$

(3) The intersection of any two soft sets in $\Im$ belongs to $\mathfrak{I}$.

The triplet $(X, \mathfrak{I}, E)$ is called a soft topological space over $X$.

Proposition 2.11. ([13]) Let $(X, \mathfrak{J}, E)$ be a soft topological space over $X$. Then the collection

$\mathfrak{J}_{e}=\{F(e) ;(F, E) \in \mathfrak{J}\}$ for each $e \in E$, defines a topology on X.

Definition 2.12. ([13]) Let $(X, \Im, E)$ be a soft topological space over $X$ and $(F, E)$ be a soft set over. Then the soft closure of $(F, E)$, denoted by $\overline{\overline{(F, E)}}$ is the intersection of all soft closed super sets of $(F, E)$. Clearly $\overline{\overline{(F, E)}}$ is the smallest soft closed set over $X$ which contains $(F, E)$.

\section{P-SEPARATION AXIOMS IN SUPRA SOFT TOPOLOGICAL SPACES}

Definition 3.1. ([1]) Let $(F, E)$ be a soft set over X. The soft set $(F, E)$ is called a soft point, denoted by $\left(x_{e}, E\right)$, if for the elemente $\in E ; F(e)=\{x\}$ and $F\left(e^{\prime}\right)=\varphi$ for all $e^{\prime} \in E-\{e\}$ (briefly denoted by $x_{e}$.)

Definition 3.2. ([22]) Two soft points $\left(x_{e}, E\right)$ and $\left(y_{e^{\prime}}, E\right)$ over a common universe $X$, we say that the soft points are different if $x \neq y$ or $e \neq e^{\prime}$.

Proposition 3.3. ([22]) Let $(F, E)$ be a soft set over. Then $(F, E)$ is the union of its soft points.

Definition 3.4. ([22]) the soft point $\left(x_{e}, E\right)$ is said to be belonging to the soft $\operatorname{set}(F, E)$, denoted by $\left(x_{e}, E\right) \in(F, E)$; if for the elemente $\in E .\{x\} \subset$ $F(e)$.

Definition 3.5. ([19]) Let $\mu$ be the collection of soft sets over a universe $X$ with a fixed set of

Parameters $E$. Then $\mu$ is called a supra soft topology on $X$ with a fixed set $E$ if

(1) $\varphi, \tilde{X} \in \mu$

(2) The union of any number of soft sets in $\mu$ belongs to $\mu$.

$(X, \mu, E)$ is called a supra soft topological space and the members of $\mu$ are called a supra soft open set. A soft set $(F, E)$ is supra soft closed set iff its complement $(F ; E)^{c}$ is a supra soft open set. It is clear that supra soft topological spaces are very natural generalization of supra topological spaces.

Definition 3.6. ([19]) Let $(X, \mu, E)$ be a supra soft topological space then $\left(F \in S_{E}(X)\right.$. Then

1) $(F, E)$ is supra soft pre-open set if $(F, E) \subseteq \operatorname{Sint}(\operatorname{Scl}((F, E))$ and

2) $(F, E)$ Supra soft pre-closed set of $\mathrm{X}$ if $(F, E) \supseteq \operatorname{Scl}(\operatorname{Sint}(F, E)))$

The set of all Supra pre-open soft sets is denoted by $\operatorname{SPOS}(X)$ and supra soft pre-closed set is denoted by $\operatorname{SPCS}(X)$

Proposition 3.7. The collection $\mathfrak{\Im}^{*}$ of all supra soft pre-closed sets in a supra soft topological space.

$(X, \mu, E)$ Satisfies the following conditions:

i) $\varphi, \tilde{X} \in \mathfrak{J}^{*}$

ii) The intersection of any number of supra soft pre-closed sets in $\mathfrak{J}^{*}$ belongs to $\mathfrak{J}^{*}$.

Proof: It is obvious.

Remark 3.8. ([19]) every soft topological space is a supra soft topological space, but the converse is not true in general as shown in the following example.

Example 3.9. Let $=\left\{h_{1}, h_{2}, h_{3}, h_{4}\right\} \quad ; \quad E=\left\{e_{1}, e_{2}\right\}$ and $X=$ $\left\{\varphi, \tilde{\tilde{X}},\left(F_{1}, E\right),\left(F_{2}, E\right),\left(F_{3}, E\right)\right\}$

Where $\left(F_{i}, E\right)$ are soft sets over $X, 1 \leq i \leq 3$, defined as follows:

$F_{1}\left(e_{1}\right)=\left\{h_{1}, h_{4}\right\} ; F_{1}\left(e_{2}\right)=\left\{h_{1}, h_{3}\right\}$

$F_{2}\left(e_{1}\right)=\left\{h_{2}, h_{4}\right\} ; F_{2}\left(e_{2}\right)=\left\{h_{2}, h_{3}\right\}$

$F_{3}\left(e_{1}\right)=\left\{h_{1}, h_{2}, h_{4}\right\} ; F_{3}\left(e_{2}\right)=\left\{h_{1}, h_{2}, h_{3}\right\}$

Then $(X, \mu, E)$ is a supra soft topological space over $X$; but it is not a soft topological space.

Definition 3.10. $([19,23])$ Let $(X, \Im, E)$ be a soft topological space and $(X, \mu, E)$ be a supra soft topological space. Then $\mu$ is a supra soft topology associated with $\widetilde{\Im}$ if $\subseteq \mu$.

Remark 3.11.i) The intersection of two supra soft pre-open sets need not supra soft open set.

ii) The intersection of a soft preopen set and a supra soft preopen set need not be supra soft preopen set.

But if $=\mathrm{SS}(\mathrm{X})_{E},(F, E) \in \mathfrak{I}$ and $(G, E) \in$, then $(F, E) \cap(G, E) \in \mu$.

Definition 3.12. Let $(X, \mathfrak{J}, E)$ be a supra soft topological space over X . A soft set $(F, E)$ in $(\mathrm{X}, \mathfrak{J}, \mathrm{E})$ is called a supra soft neighbourhood of the soft point $\left(x_{e}, E\right) \in(\mathrm{F}, \mathrm{E})$ if there exists a supra soft preopen set $(G, E)$ such that $\left(x_{e}, E\right) \in(G, E) \subset(\mathrm{F}, \mathrm{E})$.

The supra soft neighbourhood system of a soft point $\left(x_{e}, E\right)$, denoted by $U\left(x_{e}, E\right)$, is the family of all its neighbourhoods.

Theorem3.13. The supra soft neighbourhood system $U\left(x_{e}, E\right)$ at $\left(x_{e}, E\right)$ in a supra soft topological space $(\mathrm{X}, \mathfrak{J}, \mathrm{E})$ has the following properties: 1) If $(F, E) \in U\left(x_{e}, E\right)$ then $\left(x_{e}, E\right) \in(F, E)$ where $(F, E)$ is soft pre-open set.

2) If $(F, E) \in U\left(x_{e}, E\right)$ and $(F, E) \subset(G, E)$, then $(G, E) \in U\left(x_{e}, E\right)$, where $(F, E)$ and $(G, E)$ are soft pre-open sets

3) $\operatorname{If}(F, E) \in U\left(x_{e}, E\right)$, then there is a $(G, E) \in U\left(x_{e}, E\right)$ such that $(F, E) \in$ 


$$
\left.U\left(y_{e^{\prime}}, E\right)\right) \text { for each }\left(y_{e^{\prime}}, E\right) \in(G, E) \text {. }
$$

Definition3.14. Let $(X, \Im, E)$ be a supra soft topological space and $(F, E)$ be a supra soft pre-open set over $X$. The soft point $\left(x_{e}, E\right) \in(F, E)$ is called a soft interior point of a soft set $(F, E)$ if there exists a supra soft pre-open set $(G, E) \in U\left(x_{e}, E\right)$ such that $\left(x_{e}, E\right) \in(G, E) \subset(F, E)$.

Definition 3.15. Let (X, I, E) be a supra soft topological space and $(F, E)$ be a soft pre-open set over $X$.Then the supra soft interior of $(F, E)$, denoted by $(F, E)^{\circ}$, is the union of all supra soft pre-open sub sets of $(F, E)$.

Theorem 3.16. Let (X, Э, E) be a supra soft topological space and $(F, E)$ be a supra soft pre-open set over $\mathrm{X}$. Then $(F, E)=\bigcup_{e \in E}\left\{\left(x_{e}, E\right) ;\left(x_{e}, E\right)\right.$ is any soft interior point of $(F, E)$ for each $e \in E\}$.

Proposition 3.17. Let (X,, E) be a supra soft topological space and $(F, E)$ be a soft set over $X$. Then $(F, E)$ is a supra soft pre-open set if $(F, E)$ is a supra soft neighborhood of its soft points.

Definition 3.18. Let $(X, \Im, E)$ be a supra soft topological space, $(F, E)$ be a soft pre-open set over $X$ and $\left(x_{e}, E\right)$ be a soft point. Then $\left(x_{e}, E\right)$ is said to be a soft tangency point of $(F, E)$ if $(F, E) \cap(G, E) \neq \varphi$.

for arbitrary $(G, E) \in U\left(x_{e}, E\right)$.

Theorem 3.19. Let $(\mathrm{X}, \mathfrak{J}, \mathrm{E})$ be a supra soft topological space and $(F, E)$ be a soft pre-open set over X. Then $(F, E)$ is a supra soft pre closed set in $X$ if and only if every soft tangency point of $(F, E)$ belongs to it.

Proof. Let $(F, E)$ be a supra soft pre closed set, $\left(x_{e}, E\right)$ be a soft tangency point and $\left(x_{e}, E\right) \notin(F, E)$.Then $\left(x_{e}, E\right)(F, E)^{c}$. Since $(F, E)^{c}$ is a supra soft preopen set in $\mathfrak{J}$, it is a supra soft neighbourhood of $\left(x_{e}, E\right)$.Then $(F, E)^{c} \cap$ $(F, E)=\varphi$. It follows that $\left(x_{e}, E\right) \in(F, E)$.

Conversely, $\left(x_{e}, E\right) \in(F, E)^{c}$ be any soft point. Then $\left(x_{e}, E\right) \in(F, E)$. Since $\left(x_{e}, E\right)$ is not

a soft tangency point of $(F, E)$, there exists a supra soft pre neighbourhood $(G, E)$ of $\left(x_{e}, E\right)$ such that $(F, E) \cap(G, E)=\varphi$. Since $\left(x_{e}, E\right) \in(G, E) \subset$ $(F, E)^{c}$, we have that $(F, E)^{c}$ is a supra soft preopen set, i.e. $(F, E)$ is a supra soft pre-closed set.

Proposition 3.20. Let $(X, \Im, E)$ be a supra soft topological space, $(F, E)$ be a supra soft preopen set over $X$ and $x \in X$. If $\left(x_{e}, E\right)$ is a soft interior point of $(F, E)$, then $\mathrm{x}$ is an interior point of

$F(e)$ in $\left(\mathrm{X}, \mathfrak{J}_{e}\right)$

Proof. For anye $\in E, F(e) \subset X$. If $\left(x_{e}, E\right)$ is a soft pre-interior point of $(F, E)$, then there exists soft preopen set

$(G, E) \in \mathfrak{J}$ Such that $\left(x_{e}, E\right) \in(G, E) \subset(F, E)$. This means that, $x \in$ $G(e) \subset F(e)$ and $G(e) \in \mathfrak{J}_{e} \cdot x$ is an pre-interior point of $F(e)$ in $\mathfrak{I}_{e}$

Proposition 3.21. Let $(X, \mathfrak{J}, \mathrm{E})$ be a supra soft topological space, $(F, E)$ be a supra pre-open soft set over $X$ and $x \in X$. If $x$ is a tangency point of $F(e)$ in $\left(\mathrm{X}, \mathfrak{J}_{e}\right)$, then $\left(x_{e}, E\right)$ is a soft tangency point of $(F, E)$.

Remark 3.22. The converse of Proposition 3.20 and Proposition 3.21 do not hold in general.

Example 3.23. Let $X=\left\{x_{1}, x_{2}, x_{3}\right\} ; E=\left\{e_{1}, e_{2}\right\}$ and

$\mathfrak{I}=\left\{\varphi, \tilde{\tilde{X}},\left(F_{1}, E\right),\left(F_{2}, E\right),\left(F_{3}, E\right)\right\}$ Where

$F_{1}\left(e_{1}\right)=\left\{x_{1}, x_{2}\right\} ; F_{1}\left(e_{2}\right)=\left\{x_{1}, x_{3}\right\}$

$F_{2}\left(e_{1}\right)=\left\{x_{2}\right\} ; F_{2}\left(e_{2}\right)=\left\{x_{2}, x_{3}\right\}$

$F_{3}\left(e_{1}\right)=\left\{x_{1}, x_{2}\right\} ; F_{3}\left(e_{2}\right)=X$

Then $(X, \mathfrak{J}, E)$ is a supra soft topological space over $X$. Thus $(F, E)$ is defined as follows:

$F\left(e_{1}\right)=\left\{x_{1}, x_{3}\right\} ; F\left(e_{2}\right)=\left\{x_{1}, x_{3}\right\}$

Then there is not soft interior point of $(F, E)$. But $x_{1}$ and $x_{3}$ are interior points of $F\left(e_{2}\right)$ in $\Im_{e 2}$.

Here, $\widetilde{J}_{e 2}=\left\{\varphi, \tilde{X},\left\{x_{1}, x_{3}\right\},\left\{x_{2}, x_{3}\right\}\right\}$.

Definition 3.24. Let $(X, \mathfrak{I}, E)$ be a supra soft topological space and $\left(x_{e}, E\right) \neq\left(y_{e^{\prime}}, E\right)$.

i) If there exist two supra soft pre-open sets $(F, E)$ and $(G, E)$ such that

$\left(x_{e}, E\right) \in(F, E)$ and $\left(y_{e^{\prime}}, E\right) \notin(F, E)$ or $\left(y_{e^{\prime}}, E\right) \in(G, E)$ and $\left(x_{e}, E\right) \notin$ $(G, E)$,

Then $(\mathrm{X}, \mathfrak{J}, \mathrm{E})$ is called a supra soft $P_{0}$ - space.

ii) If there exist two supra soft preopen sets $(F, E)$ and $(G, E)$ such that $\left(x_{e}, E\right) \in(F, E)$ and $\left(y_{e^{\prime}}, E\right) \notin(F, E)$ and $\left(y_{e^{\prime}}, E\right) \in(G, E),\left(x_{e}, E\right) \notin$ $(G, E)$
Then $(\mathrm{X}, \mathfrak{J}, \mathrm{E})$ is called a supra soft $P_{1}$ - space.

iii) If there exist two supra soft pre-open sets $(F, E)$ and $(G, E)$ such that $\left(x_{e}, E\right) \in(F, E),\left(y_{e^{\prime}}, E\right) \in(F, E)$ and $(F, E) \cap(G, E)=\varphi$

Then $(\mathrm{X}, \mathfrak{J}, \mathrm{E})$ is called a supra soft $P_{2}$ - space.

Theorem 3.25. Let (X, I, E) be a supra soft topological space over X. Then $(\mathrm{X}, \mathfrak{\Im}, \mathrm{E})$ is a supra soft $P_{1}$-space if and only if each soft point is a supra soft pre-closed set.

Proof. Let (X, $\Im, E)$ be a supra soft $P_{1}$ - space and $\left(x_{e}, E\right)$ be an arbitrary soft point. We show that $\left(x_{e}, E\right)^{C}$ is a supra soft pre-open set. $\operatorname{Let}\left(y_{e^{\prime}}, E\right) \in$ $\left(x_{e}, E\right)^{C},\left(x_{e}, E\right) \neq\left(y_{e^{\prime}}, E\right)$. Since $(\mathrm{X}, \mathfrak{J}, \mathrm{E})$ is a supra Soft $P_{1}$ - space, there exists a supra soft pre-open set $(G, E)$ such that $\left(y_{e^{\prime}}, E\right) \in(G, E),\left(x_{e}, E\right) \notin$ $(G, E)$.Then $\left(y_{e^{\prime}}, E\right) \in(G, E) \subset\left(x_{e}, E\right)^{C}$. This implies that $\left(x_{e}, E\right)^{C}$ is a supra soft pre-open set, i.e. $\left(x_{e}, E\right)$ is a supra soft Pre-closed set.

Suppose that for each $\left(x_{e}, E\right)$ is a supra soft pre-closed set in . Then $\left(x_{e}, E\right)^{C}$ is a supra soft pre-open set in $\mathfrak{J} \cdot \operatorname{Let}\left(x_{e}, E\right) \neq\left(y_{e^{\prime}}, E\right)$. Thus $\left(y_{e^{\prime}}, E\right) \in\left(x_{e}, E\right)^{C}$ and $\left(x_{e}, E\right) \notin\left(x_{e}, E\right)^{C}$. Similarly $\left(y_{e^{\prime}}, E\right)^{C}$ is a supra soft pre-open set in $\mathfrak{J}$ such that $\left(x_{e}, E\right) \in\left(y_{e}, E\right)^{C}$ and $\left(y_{e^{\prime}}, E\right) \notin\left(y_{e^{\prime}}, E\right)^{C}$. Therefore $(\mathrm{X}, \mathfrak{I}, \mathrm{E})$ is a supra soft $P_{1}$ - space over X.

Proposition 3.26. Let (X, I, E) be a supra soft topological space. If $(\mathrm{X}, \mathfrak{J}, \mathrm{E})$ is a supra soft $P_{i}$-space, then $\left(X, \mathfrak{J}_{e}\right)$ is a supra $P_{i}$-space for each $e \in E .(\mathrm{i}=0,1$,

\section{Remark 3.27.}

a) Ever $\neq$ y supra soft $P_{1}$ - space is a supra soft $P_{0}$ - space.

b) Every supra soft $P_{2}$ - space is a supra soft $P_{1}$ - space.

Example 3.28. Let $=\left\{x_{1}, x_{2}\right\}, E=\left\{e_{1}, e_{2}\right\}$ and $\mathfrak{I}=\{\varphi, \tilde{X},(F, E)\}$ where $F\left(e_{1}\right)=\left\{x_{1}\right\}, F\left(e_{2}\right)=X$

Then $(X, \mathfrak{J}, E)$ is a supra soft topological space over $X .(X, \mathfrak{J}, E)$ is a supra soft $P_{0}$ - space. over $X$ which is not a supra soft $P_{1}$ - space.

Theorem 3.29. Let (X, $\Im, E$ ) be a supra soft $P_{1}$ - space., for every soft point $\left(x_{e}, E\right),\left(x_{e}, E\right) \in(G, E)$ and $(G, E) \in \mathfrak{J}$. If there exists a supra soft preopen set $(F, E)$ such that $\left(x_{e}, E\right) \in(F, E) \subset c l^{s}(F, E) \subset(G, E)$ then $(\mathrm{X}, \mathfrak{J}$, E) is a supra soft $P_{2}$-space.

Proof. Suppose that $\left(x_{e}, E\right) \neq\left(y_{e^{\prime}}, E\right)$. Since $(\mathrm{X}, \mathfrak{J}, \mathrm{E})$ is a supra soft $P_{1}$ space, $\left(x_{e}, E\right)$ and $\left(y_{e^{\prime}}, E\right)$ are supra soft pre-closed sets in $\mathfrak{J}$. Thus $\left(x_{e}, E\right) \in\left(y_{e}, E\right)^{C}$ and $\left(y_{e}, E\right)^{C}$ is a supra soft pre-open set in $\mathfrak{\Im}$. Then there exists a supra soft pre-open set $(F, E)$ in $\mathfrak{J}$ such that $\left(x_{e}, E\right) \in(F, E) \subset$ $c l^{S}(F, E) \subset\left(y_{e l}, E\right)^{C}$

Hence we have $\left(y_{e}, E\right)^{C} \in\left(c l^{s}(F, E)\right)^{c}, \quad\left(x_{e}, E\right) \in(F, E)$ is a $(F, E) \cap$ $\left(c l^{s}(F, E)\right)^{c}=\varphi$

$(\mathrm{X}, \mathfrak{J}, \mathrm{E})$ is a supra soft $P_{2}$-space.

Definition 3.30. Let $(X, \mathfrak{I}, E)$ be a supra soft topological space over $X$. i) $(\mathrm{F}, \mathrm{E})$ be a supra soft pre-closed set in $\mathrm{X}$ and $\left(x_{e}, E\right) \notin(F, E)$. If there exist supra soft pre-open sets $\left(G_{1}, \mathrm{E}\right)$ and $\left(G_{2}, \mathrm{E}\right)$ such that $\left(x_{e}, E\right) \in\left(G_{1}, \mathrm{E}\right)$ and $(F, E) \in\left(G_{2}, \mathrm{E}\right)$ and $\left(G_{1}, \mathrm{E}\right) \cap\left(G_{2}, \mathrm{E}\right)=\varphi$ then $(\mathrm{X}, \mathfrak{I}, \mathrm{E})$ is called a supra soft pre regular space.

ii) $(\mathrm{X}, \mathfrak{J}, \mathrm{E})$ is said to be a supra soft $P_{3}$-space if it is supra soft pre-regular and supra soft $P_{1}$-space.

Remark 3.31. A supra soft $P_{3}$-space is a supra soft $P_{2}$-space.

Theorem 3.32. Let $(X, \Im, E)$ be a supra soft topological space over $X$. $(\mathrm{X}, \mathfrak{\Im}, \mathrm{E})$ is a supra soft

$P_{3}$-space iff for every $\left(x_{e}, E\right) \in(F, E) \in \Im$ I there exists soft pre-open set (G, E) $\in \mathfrak{J}$ such that $\left(x_{e}, E\right) \in(G, E) \subset c l^{s}(G, E) \subset(F, E)$.

Proof. Let $(\mathrm{X}, \mathfrak{I}, \mathrm{E})$ be a supra soft $P_{3}$-space and $\left(x_{e}, E\right) \in(F, E) \in \mathfrak{J}$. Since $(\mathrm{X}, \mathfrak{J}, \mathrm{E})$ is

a supra soft $P_{3}$-space for the soft point $\left(x_{e}, E\right)$ and supra soft pre closed set $(F, E)^{c}$; there exists soft pre-open sets $\left(G_{1}\right.$, E) and $\left(G_{2}\right.$, E) $\in \mathfrak{J}$ such that $\left(x_{e}, E\right) \in\left(G_{1}, \mathrm{E}\right),(F, E)^{c} \subset\left(G_{2}, \mathrm{E}\right)$ and $\left(G_{1}, \mathrm{E}\right) \cap\left(G_{2}, \mathrm{E}\right)=\varphi$.Thus, we have $\left(x_{e}, E\right) \in\left(G_{1}, \mathrm{E}\right) \subset\left(G_{2}, E\right)^{c} \subset(F, \mathrm{E})$. Since $\left(G_{2}, E\right)^{c}$ is supra soft preclosed, $c l^{S}\left(G_{1}, E\right) \subset\left(G_{2}, E\right)^{c}$.

Conversely, let $\left(x_{e}, E\right) \notin(H, E)$ and $(\mathrm{H}, \mathrm{E})$ be a supra soft pre-closed set. Thus, $\left(x_{e}, E\right) \in(G, E)^{C}$ and from the condition of the theorem, we have $\left(x_{e}, E\right) \in(G, E) \subset \mathrm{Cl}^{S}(G, E) \subset(H, E)^{C} \quad:$ Then $\quad\left(x_{e}, E\right) \in(G, E)$, $(H, E) \subset\left(c l^{S}(H, E)\right)^{C}$ and $(G, E)\left(c l^{S}(G, E)\right)^{C}=\varphi$ are satisfied, i.e. $(\mathrm{X}, \mathfrak{J}$, E) is a supra soft $P_{3}$-space.

Theorem 3.33. Let $(\mathrm{X}, \mathfrak{I}, \mathrm{E})$ be a supra soft topological space over X. If $(\mathrm{X}, \mathfrak{I}, \mathrm{E})$ is a supra soft $P_{3}$-space, then $\left(\mathrm{X} ; \mathfrak{J}_{e}\right)$ is a supra $P_{3}$-space, for each $e \in E$.

Proof. Let $(X, \mathfrak{I}, \mathrm{E})$ be a supra soft topological space over X. By Proposition

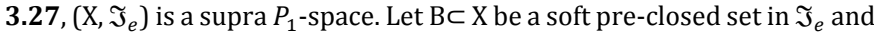
$x \notin B$. From the definition of $\mathfrak{J}_{e}$, there exists a soft pre closed set $(\mathrm{F}, \mathrm{E})$ and $\left(x_{e}, E\right) \notin(F, E)$ such that $F(e)=B$. Since $(\mathrm{X}, \mathfrak{J} E)$ is a supra soft pre 
regular space, there exist supra soft pre-open sets

$\left(G_{1}, \mathrm{E}\right)$ and $\left(G_{2}, \mathrm{E}\right)$ such that $\left(x_{e}, E\right) \in\left(G_{1}, \mathrm{E}\right),(F, E) \subset\left(G_{2}, \mathrm{E}\right)$ and $\left(G_{1}, \mathrm{E}\right) \cap$ $\left(G_{2}, \mathrm{E}\right)=\varphi$

Thus, we have $x \in G_{1}(e), B \subset G_{2}(e)$ and $G_{1}(\mathrm{e}) \cap G_{2}(\mathrm{e})=\varphi$

i.e. $\left(\mathrm{X}, \mathfrak{J}_{e}\right)$ is a supra $P_{3}$-space for eache $\in E$.

Definition 3.34.i) Let (X, J, E) be a supra soft topological space $(F, E)$ and (G,E) supra soft

Preclosed sets such that $(F, \mathrm{E}) \cap(G, \mathrm{E})=\varphi$ : If there exist supra soft preopen $\operatorname{sets}\left(F_{1}, \mathrm{E}\right)$ and $\left(F_{2}, \mathrm{E}\right)$ such that $(F, E) \subset\left(F_{1}, \mathrm{E}\right),(\mathrm{G}, \mathrm{E}) \subset\left(F_{2}, \mathrm{E}\right)$ and $\left(F_{1}, \mathrm{E}\right) \cap\left(F_{2}, \mathrm{E}\right)=\varphi$ then $(\mathrm{X}, \mathfrak{J}, \mathrm{E})$ is called a supra soft pre normal space.

ii) $(\mathrm{X}, \Im, \mathrm{J})$ is said to be a supra soft $P_{4}$-space if it is supra soft pre-normal and supra soft $P_{1}$-space.

Remark 3.35. A supra soft $P_{4}$-space is a supra soft $P_{3}$-space.

Theorem 3.36. Let (X, I, E) be a supra soft topological space over X. Then $(\mathrm{X}, \mathfrak{J}, \mathrm{E})$ is a supra soft $P_{4}$--space if and only if, for each supra soft preclosed set $(\mathrm{F}, \mathrm{E})$ and supra soft pre-open set $(D, E)$ with

$(F, E) \subset(G, E)$, there exists supra soft pre-open set $(D, E)$ such that $(F, E) \subset(D, E) \subset \operatorname{cls}(D, E) \subset(G, E)$

Proof. Let $(\mathrm{X}, \mathfrak{J}, \mathrm{E})$ be a supra soft $P_{4}$-space, $(F, E)$ be a supra soft preclosed set and $(F, E) \subset(G, E),(G, E) \in \mathfrak{J}$. Then $(G, E)^{C}$ is a supra soft preclosed set and $(F, E) \cap(G, E)^{C}=\varphi$

Supra soft $P_{4}$-space, there exist supra soft pre-open sets $\left(D_{1}, E\right)$ and $\left(D_{2}, E\right)$ such that

$(F, E) \subset\left(D_{1}, E\right)$

$(G, E)^{C} \subset\left(D_{2}, E\right) \quad,\left(D_{1}, E\right) \cap\left(D_{2}, E\right)=\varphi$.Implies $\quad(F, E) \subset\left(D_{1}, E\right) \subset$ $\left(D_{2}, E\right)^{C} \subset(G, E)$.

$\left(D_{2}, E\right)^{C}$ is a supra soft pre-closed set and $\operatorname{cls}\left(D_{1}, E\right) \subset\left(D_{2}, E\right)^{C}$ is satisfied. Thus

$(F, E) \subset(D, E) \subset \operatorname{precls}\left(D_{1}, E\right) \subset(G, E)$ is obtained.

Conversely, let $\left(F_{1}, E\right)$ and $\left(F_{2}, E\right)$ be two supra soft Pre-closed sets and $\left(F_{1}, E\right) \cap\left(F_{2}, E\right)=\varphi$. Then $\left(F_{1}, E\right) \subset\left(F_{2}, E\right)^{C}$. From the condition of theorem, there exists a supra soft preopen set (D, E) such that $\left(F_{1}, E\right) \subset$ $(D, E) \subset \operatorname{cls}(D, E) \subset\left(F_{2}, E\right)^{C}$

So $(D, E),(\operatorname{cls}(D, E))^{C}$ are supra soft preopen sets and $\left(F_{1}, E\right) \subset(D, E)$, $\left(F_{2}, E\right) \subset(c l s(D, E))^{C}$

And $(D, E) \cap(\operatorname{cls}(D, E))^{C}=\varphi$ are obtained. Hence is a supra soft $P_{4}$-space.

\section{CONCLUSION}

We have introduced separation axioms in supra soft topological spaces which are defined over an initial universe with a fixed set of parameters. Later their important properties are investigated with respect to soft preopen sets.

\section{REFERENCES}

[1] Zadeh, L.A. 1965. Fuzzy sets. Information and Control, 8, 338-353.

[2] Atanassov, K. 1986. Intuitionistic fuzzy sets. Fuzzy Sets and Systems, 20 (1), 87-96.

[3] Pawlak, Z. 1982. Rough sets. International Journal of Information of Computer Science, 11, 341-356.

[4] Molodtsov, D. 1999. Soft set theory-first results. Computers and Mathematics with Applications, 37, 19-31.

[5] Maji, P.K., Roy, A.R., Biswas, R. 2002. An Application of soft sets in a decision-making problem. Computers and Mathematics with Applications, 44 (2), 1077-1083.

[6] Aktas, H., Cagman, N. 2007. Soft sets and soft group. Information Science, 177 (2), 2726-2735.

[7] Acar, U., Koyuncu, F., Tanay, B. 2010. Soft sets and soft rings. Computers and Mathematics with Applications, 59 (2), 3458-3463.

[8] Feng, F., Jun, Y.B., Zhao, X. 2008. Soft semi rings. Computers and Mathematics with Applications, 56 (10), 2621-2628.

[9] Kandil, A., Tantawy, O.A.E., El-Sheikh, S.A., Hazza, S.A. 2016. Pairwise open (closed) soft sets in soft bi topological spaces. Annals of Fuzzy Mathematics and Informatics, 11 (4), 571-588.

[10] Shabir, M., Ali, M.I. 2009. Soft ideals and generalized fuzzy ideals in semi groups. New Mathematics and Natural Computation, 5, 599-615.
Computers and Mathematics with Applications, 62 (1), 2480-2486.

[12] Aras, C.G., Bayramov, S. 2011. Fuzzy soft modules. International Mathematical Forum, 6 (11), 517-527.

[13] Shabir, M., Naz, M. 2011. On soft topological spaces. Computers and Mathematics with Applications, 61, 1786-1799.

[14] Cagman, N., Karatas, S., Enginoglu, S. 2011. Soft topology. Computers and Mathematics with Applications, 62 (1), 351-358.

[15] Min, W.K. 2011. A note on soft topological spaces. Computers and Mathematics with Applications, 62 (2), 3524-3528.

[16] Sabir, H., Bashir, A. 2011. Some properties of soft topological spaces. Computers and Mathematics with Applications, 62 (13), 4058-4067.

[17] Zorlutana, I., Akdag, M., Min, W.K., Atmaca, S. 2012. Remarks on soft topological spaces. Annals of Fuzzy Mathematics and Informatics, 3(2), 171-185.

[18] Mashhour, A.S., Allam, A.A., Mahmoud, F.S., Khedr, F.H. 1983. On supra topological spaces. Indian Journal of Pure and Applied Mathematics, 14(4), 502-510.

[19] El-Sheikh, S.A., Abd El-latif, A.M. 2014. Decomposition of Some Types of Supra Soft Sets and Soft Continuity. International Journal of Mathematics Trends and Technology, 9(1), 37-56.

[20] Ittanagi, B.M. 2014. Soft bi topological spaces. International Journal of Computer Applications, 107 (7), 1-4.

[21] Ali, M.I., Feng, F., Liu, X.Y., Min, W.K., Shabir, M. 2009. On some new operations in soft set theory. Computers and Mathematics with Applications, 57 (2), 1547-1553.

[22] Bayramov, S., Gunduz, C. 2013. Soft locally compact spaces and soft paracompact spaces. International Journal of Mathematics and Systems Science, 3 (1), 122-130.

[23] Sun, Q.M., Zhang, Z.L., Liu, J. 2008. Soft sets and soft modules. Lecture Notes in Computer Science, 5009(2), 403-409.

[11] Aras, C.G., Bayramov, S. 2011. Intuitionistic fuzzy soft modules. 